\title{
A Economia Solidária como um Instrumento de giro Decolonial do saber Econômico Capitalista
}

\author{
Recebido: 20-11-2017 \\ Aprovado: 26-07-2018 \\ Thiago Moreira de Carvalho ${ }^{1}$ \\ Luiz Guilherme de Oliveira $^{2}$ \\ Mariana Lima Cruz de Almeida ${ }^{3}$ \\ Polliana Cristina Oliveira de Carvalho ${ }^{4}$
}

\section{Introdução}

A colonialidade discrimina, impõe vontades e conhecimentos, inferioriza o ser, impõe modelos de sociedade, principalmente na latino-americana, pautada na exploração, no Apartheid, na vontade do homem, na subjugação de pessoas negras, indígenas, mestiças, crianças e mulheres. Trata-se de um modelo procustiano que legitima um

\begin{abstract}
${ }^{1}$ Doutorando em Ciências Sociais pela Universidade de Brasília (UnB), Mestre em Agronegócios pela Universidade de Brasília (UnB), possui graduação em Direito e Psicologia pelo Instituto de Educação Superior de Brasília (IESB). Foi professor do Curso de Gestão em Agronegócios/UnB e atualmente é professor do Curso de Direito da Universidade Católica de Brasília/UCB e Faculdade Projeção/FAPRO. Consultor Jurídico da Confederação Nacional da Agricultura e Pecuária do Brasil (CNA) e do Sindicato dos Avicultores do Distrito Federal (Sindiaves\DF). Advogado Chefe do Escritório Oliveira e Carvalho Advocacia. Contato: tdecarvalho@ymail.com

${ }^{2}$ Economista. Pós doutorado École des Hautes Études en Science Sociales (EHESS, Paris/França), 2015. Pós doutorado Columbia University - School of International and Public Affairs (SIPA, Nova Iorque/EUA), 2011. Doutor em Política Científica e Tecnológica (DPCT/Unicamp), 2005. Mestre em Economia (PUC/SP), 1998. Professor Associado II da Universidade de Brasília (UnB). Professor Visitante na Columbia University - SIPA (School of International and Public Affairs) - Cátedra Ruth Cardoso NYC/EUA, 2012. Pesquisador do Centro de Estudos Avançados de Governo e Administração Pública (CEAG-UnB). Foi bolsista da Fapesp, Capes, CNPq e Comissão Fulbright. Contato: lgoliveira@unb.br

${ }^{3}$ Possui graduação em Ciências Sociais - Licenciatura pela Universidade de Brasília (2011) e graduação em Ciências Sociais com habilitação em Antropologia pela Universidade de Brasília (2011). Foi assistente de pesquisa I do Instituto de Pesquisa Econômica Aplicada - DF, no projeto de pesquisa II Pesquisa Nacional do Pronera (Programa Nacional de Educação na Reforma Agrária). Concluiu o Curso de Pós-Graduação - Residência Agrária em Direitos Sociais do Campo, na UFG, campus de Cidade de Goiás. Atuou na Assessoria Técnica, Social e Ambiental a Assentamentos da Reforma Agrária, com ênfase em construção de Planos de Desenvolvimento. Tem experiência na área de Educação, com ênfase em Educação Infantil e Educação Libertária. Tem experiência na área de comunicaçao e educação, atuando principalmente na produção coletiva de mídia (rádio, video e texto). Atua nos seguintes temas: corpo, arte e técnica, infância, questão agrária e gênero. Contato: tdecarvalho@ymail.com
\end{abstract}

4 Mestre em Letras. Bacharel em Direito e Letras. Advogada e professora. Contato: oliveira@oliveiraecarvalho.adv.br 
grupo minoritário e lança mão de regras universalizantes de modos de vida, de produção e de conhecimento.

Uma das formas de reprodução do modelo colonialista é por meio do saber elemento este que será o foco deste artigo. Será discutida uma das alternativas de produção do saber econômico frente ao capitalismo, o qual influencia as formas de produção, estruturas sociais e relações humanas da sociedade brasileira.

A economia capitalista visa o lucro. Transforma os membros de uma sociedade em seres individualistas, sem se importar com os seus desdobramentos. Impõe novos conhecimentos que oprimem os conhecimentos locais, inferiorizando as perspectivas que não se originam das mesmas fontes europeias.

Como uma tentativa de romper este modelo, há a economia solidária, um modo de produção que se caracteriza pela igualdade de direitos. Os meios de produção são de posse coletiva dos que trabalham com eles - essa é a característica central. E a autogestão, ou seja, os empreendimentos de economia solidária são geridos pelos próprios trabalhadores coletivamente de forma democrática. Além disso, utiliza-se como base para este meio de produção conhecimentos locais, contrários ao modelo eurocêntrico claustrofóbico e aprisionador.

O capitalismo, munido do imaginário de legitimidade colonialista, dita que a maioria dos indivíduos é destituída de poder, porque deve ter menos capacidade. São pessoas, segundo este sistema, que não se adequam ao padrão estabelecido, logo, são desprezíveis e devem ser subjugados. Esse raciocínio se sustenta no pressuposto de que numa economia de livre mercado os ganhadores na competição têm que ser os melhores.

Essa estrutura que discrimina deve ser, por óbvio, repensada, especificamente, deve haver uma ruptura da colonização do saber econômico, com o intuito de possibilitar novas formas de o indivíduo interagir com o conhecimento, com os seus recursos e com os outros seres humanos.

Assim, a proposta deste trabalho é sugerir o desenvolvimento da economia solidária como alternativa de produção do saber econômico, com a finalidade de promover conhecimentos e práticas que possibilitem um giro decolonial. 


\section{Colonialidade e o Giro Decolonial}

A modernidade, segundo Dussel (2000, p. 49), é um "mito" que oculta a colonialidade. Segundo o autor (2000, p.49), na colonialidade "a civilização moderna autodescreve-se como mais desenvolvida e superior (o que significa sustentar inconscientemente uma posição eurocêntrica)". Outra característica da modernidade liga-se ao fato de que o conhecimento e seu processo educativo de "desenvolvimento devem ser aqueles seguidos pela Europa (é, de fato, um desenvolvimento unilinear e a Europa que determina, novamente de modo inconsciente, a falácia desenvolvimentista)" (DUSSEL, 2000, p. 49).

$\mathrm{O}$ processo de colonização foi "determinante historicamente para o desenvolvimento ou subdesenvolvimento dos países americanos, atingindo também o processo de produção do conhecimento" (PONTES \& TAVARES, 2014, p.4). Atualmente, não se vive mais a relação de colonização entre metrópole e colônia, mas sim, uma relação ressignificada, a qual Grosfoguel (2008, p.55) denomina de "colonialidade". O termo colonialidade "permite-nos compreender a continuidade das formas coloniais de dominação após o fim das administrações coloniais, produzidas pelas culturas coloniais e pelas estruturas do sistema-mundo capitalista moderno/colonial" (GROSFOGUEL, 2008, p.55).

A partir desse breve conceito, Mignolo (2003, p. 30) acrescenta que a colonialidade possui uma tripla dimensão: a do poder, do saber e do ser. Elementos estes que serão debatidos neste artigo, com o intuito de alcançar a ruptura destes por meio da Economia solidária.

O sociólogo peruano Aníbal Quijano acrescenta ao debate o conceito de colonialidade do poder, que se refere "à sobrevivência dos legados do colonialismo em Estados-nação independentes” (apud BERNADINO-COSTA, 2007, p. 313). Segundo Quijano (2000, p.1) “o fenômeno do poder é caracterizado como um tipo de relação social constituído pela presença permanente de três elementos: dominação, exploração e conflito", que influenciam o trabalho, o sexo, a autoridade coletiva (ou pública), a subjetividade/intersubjetividade, além de seus recursos e produtos.

Com essa especificação do conceito de poder, observa-se que se trata de uma categoria formada por um complexo estrutural, cujo carácter é sempre histórico e específico. Em outras palavras, haverá sempre um certo padrão histórico do poder, com 
características contextuais que o compõem. O atual modelo de poder global se materializa com a articulação entre os elementos listados a seguir:

1) a colonialidade do poder, que é a ideia de "raça" como base do padrão básico universal de classificação social e dominação social;

2) o capitalismo como um padrão universal de exploração social;

3) status de controle central universal da autoridade coletiva e do moderno Estadonação como a sua variante hegemônica;

4) eurocentrismo como a forma hegemônica de controle da subjetividade / intersubjetividade, particularmente na forma de produzir conhecimento. (QUIJANO, 2000, p.1).

Por sua vez, Maldonado-Torres (2007, p.130) discorre que a colonialidade do poder "se refere à interrelação entre formas modernas de exploração e dominação". Já Grosfoguel (2008, p.55) aduz que a expressão colonialidade do poder designa:

\footnotetext{
um processo fundamental de estruturação do sistema-mundo moderno/colonial, que articula os lugares periféricos da divisão internacional do trabalho com a hierarquia étnico-racial global e com a inscrição de migrantes do Terceiro Mundo na hierarquia étnico-racial das cidades metropolitanas globais.
}

Ou seja, para o autor, os países periféricos e os povos não-europeus "vivem hoje sob o regime da colonialidade global imposto pelos Estados Unidos, através do Fundo Monetário Internacional (FMI), do Banco Mundial (BM), do Pentágono e da OTAN”. Assim, os povos que se encontram em zonas periféricas estão em situação colonial, mesmo que não estejam subordinadas a uma administração colonial (Grosfoguel, 2008, p.55).

Nessa linha de pensamento Mignolo (2010, p.12) acrescenta que a matriz colonial do poder "é uma estrutura complexa de níveis entrelaçados", relacionados ao controle da economia, da autoridade, da natureza e dos recursos naturais, do gênero e da sexualidade, da subjetividade e do conhecimento.

Sobre colonialidade do saber, Castro Gómez (2000, p.154) esclarece que "esta categoria junto à colonialidade do poder encontram-se localizadas em uma mesma matriz genética". Catherine Walsh $(2004$, p.4) corrobora com essa ideia ao estabelecer que a colonialidade do poder passa pelo campo do conhecimento. Como consequência imediata, resta explícita a hegemonia eurocêntrica na produção deste. 
Ainda sob a perspectiva de Walsh (2004,p.4), a maior consequência da geopolítica do conhecimento é "entender que o conhecimento está disposto da mesma forma que a economia: organizado mediante centros de poder e regiões subordinadas, nas quais os centros das capitais econômicas também são os centros das capitais intelectuais".

Diante do exposto, pode-se inferir que "a produção intelectual da América Latina tem pouco peso para o mundo" (WALSH, 2004, p.4), tendo em vista que a produção intelectual eurocêntrica possui poder e legitimidade. Catherine Walsh aprofunda suas reflexões sobre a produção intelectual na América Latina:

\begin{abstract}
Desta forma, percebe-se que o discurso da modernidade criou a ilusão de que o conhecimento é abstrato e deslocalizado, fazendo-nos pensar que o conhecimento é universal incorporado-de, não tem casa ou corpo, nem sexo ou cor. É este mesmo discurso da modernidade que também cria a necessidade de todas as regiões do planeta "subir" para a epistemologia da modernidade; ou seja, para cercar da América Latina para o modelo eurocêntrico como o único progresso válido no campo do conhecimento (WALSH, 2004,p.5).
\end{abstract}

Por sua vez, Pontes e Tavares (2014, p.4) aduzem que a epistemologia eurocêntrica "adquiriu um estatuto de universalidade dado que a produção de conhecimento na modernidade foi alheia aos contextos sociais que determinaram a sua produção". Segundo estes autores (2014, p.5), a consequência desta epistemologia eurocêntrica é que "a cultura dominante e hegemônica, ao silenciar todas as culturas e formas de conhecimento subalternos, impôs um modelo de racionalidade e um conjunto de valores morais, estéticos e religiosos a todos os povos sob o domínio colonial". Um desdobramento dessa "cultura dominante" é a subordinação cultural imposta para América Latina, criando, dessa forma, dependências intelectuais.

Sobre a colonialidade do ser, Maldonado-Torres $(2007$, p.129) a relaciona ao rol da epistemologia e às tarefas gerais de produção do conhecimento nas reproduções de regimes de pensamento coloniais. Em suma, a colonialidade do ser se refere, então, à experiência vivida da colonização e seu impacto na linguagem.

Com base no conceito acima, Maldonado-Torres (2008) propõe romper com este modelo de colonialidade, por meio de um verdadeiro giro decolonial. Este termo foi cunhado originalmente pelo autor supracitado, no ano de 2005 e, basicamente, significa o movimento de resistência teórico e prático, político e epistemológico à lógica da modernidade/colonialidade. 
Ainda sob a visão do autor citado, o giro decolonial representa uma mudança radical nas formas hegemônicas no centro do debate de poder, ser e saber. Não havendo mais mestres ou escravos, comprometimento a uma ética e a uma política de libertação e aos surgimentos de giros descolonizadores subjetivos.

Sobre o giro decolonial, continua o autor $(2008$, p. $)$ a afirmar que:

\begin{abstract}
Não se trata, primeiramente, de uma ideia como tal, mas um sentimento e a sensação de horror no desdobramento das formas coloniais de poder na modernidade, formas que foram responsáveis por dividir o mundo entre hierarquias de domínio e várias formas de escravidão fundamentadas, e não de diferenças étnicas ou religiosas, mas mais propriamente, em diferenças naturais presunçosamente, que está ancorado na mesma fisicalidade de indivíduos considerados não totalmente humano.
\end{abstract}

O giro decolonial deve, pois, ser tratado como uma revolução na maneira que muitos indivíduos colonizados percebem a sua realidade, sendo proposta, "então, uma mudança, não só ao nível da atitude de indivíduos ou comunidades específicas, mas ao nível de pensamento mundial" (MALDONADO-TORRES, 2008, p.70).

\title{
Economia Solidária: conceito e características
}

A economia solidária é mais que uma alternativa ao capitalismo, é uma forma diferente de produção e comércio necessários para a subsistência e desenvolvimento de determinada comunidade. Em linhas gerais, pode ser definida como o "conjunto de atividades econômicas de produção, distribuição, consumo, poupança e crédito, organizadas sob a forma de autogestão" (BRASIL, 2015) ou, ainda, "como um modo de produção que se caracteriza pela igualdade" (SINGER apud OLIVEIRA, 2008, p. 289) entre os participantes desta.

Por sua vez, Nancy Neamtan (2002, p.14) aduz que o termo economia solidária é formada pela combinação de dois outros conceitos: "economia, que se refere à concreta produção de bens ou serviços pelo negócio ou empreendimento que contribui com uma rede em prol do bem-estar coletivo". E solidariedade, que se refere ao "lucro social, oposta ao puro lucro econômico" (NEAMTAN, 2002, p.14). Este lucro social é mensurado em termos de sua contribuição ao desenvolvimento democrático de encorajamento e empoderamento do cidadão e de projetos, o qual promove o melhoramento da qualidade de vida e do bem-estar da população, especialmente por meio do melhoramento de disposição de serviços (NEAMTAN, 2002, p.14). 
Esse modo alternativo de produção tem alguns princípios norteadores, como solidariedade, igualdade, democracia, autogestão e cooperação. Explica Singer como alguns desses conceitos se relacionam à economia solidária.

Pela igualdade de direitos, os meios de produção são de posse coletiva dos que trabalham com eles - essa é a característica central. E a autogestão, ou seja, os empreendimentos de economia solidária são geridos pelos próprios trabalhadores coletivamente de forma inteiramente democrática, quer dizer, cada sócio, cada membro do empreendimento tem direito a um voto. Se são pequenas cooperativas, não há nenhuma distinção importante de funções, todo o mundo faz o que precisa. Agora, quando são maiores, aí há necessidade que haja um presidente, um tesoureiro, enfim, algumas funções especializadas, e isso é importante sobretudo quando elas são bem grandes, porque aí uma grande parte das decisões tem que ser tomada pelas pessoas responsáveis pelos diferentes setores. Eles têm que estritamente cumprir aquilo que são as diretrizes do coletivo, e, se não o fizerem a contento, o coletivo os substitui. É o inverso da relação que prevalece em empreendimentos heterogestionários, em que os que desempenham funções responsáveis têm autoridade sobre os outros. (SINGER apud OLIVEIRA, 2008, p. 289).

Segundo as considerações da V Plenária do Fórum Brasileiro de Economia Solidária, a economia solidária é uma estratégia de desenvolvimento sustentável, diverso e solidário, como alternativa de estrutura popular organizada dos trabalhadores associados. Sendo assim, termina dizendo que é "uma proposta transversal e articulada com diversos temas, sujeitos e iniciativas para o enfretamento e superação do modelo capitalista" (DUBEUX, MEDEIROS, VILAÇA, SANTOS, 2012, p. 8).

Ainda se faz necessário, por fim, dizer que não é somente uma mera alternativa ao capitalismo como se fosse qualquer outro modo de produção. Singer salienta que a economia solidária se apresenta como uma alternativa superior. Neste ponto da discussão, adverte que a superioridade não diz respeito, somente ou predominantemente, ao aspecto econômico, mas sim e principalmente, na medida em que apresenta um modelo de produção que acarreta estreitamento social e familiar (SINGER, 2002, p. 114). Singer continua explicando sobre a superioridade desta alternativa e termina dizendo que esta superioridade só se comprovará quando ofertar em parcelas crescentes de toda a população oportunidades reais de autossustento, ao ponto de que estas usufruam "o mesmo bem-estar médio que o emprego assalariado proporciona." (SINGER, 2002, p. 120). Assim, a economia solidária é um modelo baseado na autogestão e solidariedade com várias formas de empreendimento.

Referente aos seus princípios, de acordo com Neamtan (2002, p.14), a economia solidária consiste em uma junção de atividades e organizações, emergido de um 
empreendimento coletivo, que busca como princípio comum os seguintes elementos estruturais:

a) o objetivo do empreendimento da economia solidária é servir aos seus membros ou a toda comunidade, em vez de simplesmente se esforçar para adquirir o mero o lucro financeiro;

b) o empreendimento da economia solidária é autônomo do Estado;

c) nos seus estatutos e código de conduta, estabelece um processo de tomada de decisão democrática que implica a necessária participação dos membros e dos trabalhadores;

d) dá prioridade na distribuição de receitas e de excedentes às pessoas e ao trabalho, em vez de ao capital;

e) suas atividades são baseadas em princípios de participação, capacitação e responsabilidade individual e coletiva.

Com esses elementos em mente, é possível notar a importância da economia solidária para a temática do rompimento das estruturas cristalizadas da modernidade e suas formas de poder que estatizam e legitimam formas de conhecimento ditas 'universais'.

\section{Economia Solidária: instrumento de giro decolonial do saber econômico capitalista}

Escobar (2007, p.55) expõe que os colonizadores acreditam neste discurso do desenvolvimento, que atende "às exigências sociais do cientificamente verificado". No caso do campo econômico, o colonizador, por meio do FMI, do Banco Mundial (GROSFOGUEL, 2008, p.55) e crente nesta perspectiva desenvolvimentista, impõe ao colonizado sua forma de produzir, quais demandas atender e sua perspectiva epistemológica econômica. O autor (2007, p.55) aduz que o discurso desenvolvimentista "determina o que podemos pensar e dizer". Assim, a economia do colonizador impõe aos subalternos (RODRIGUEZ, 2009) suas perspectivas, seus objetivos, estruturas e dinâmicas.

Referente ao saber, Mignolo (2000) explica a existência de uma hierarquia do conhecimento e de produção do conhecimento e de teorias por partes dos europeus que subalterniza os não-europeus, reconhecendo que são produtoras de folclore ou cultura, mas não de conhecimento ou de teorias.

Assim acontece com a epistêmica econômica do colonizador, a qual considera-se neutra e superior ao conhecimento econômico local. Grosfoguel (2008, p.53) afirma que "a neutralidade e a objetividade desinserida e não-situada da geopolítica do conhecimento é um mito ocidental". 
Por sua vez, a economia solidária pode romper com essa lógica modernalcolonizadora, no aspecto do saber econômico, sendo um verdadeiro giro decolonial, conforme será exposto.

Segundo De França Filho e Laville (2004, p.111), o fenômeno da economia solidária se apresenta "numa perspectiva de busca de novas formas de regulação da sociedade, sob a forma da auto-organização social em torno de ações, ao mesmo tempo, econômicas e políticas". Da Silva (2011, p.54) acrescenta que a economia solidária democratiza "as relações sociais de produção, contribui para a emancipação do trabalho, considerando o ser humano na sua integralidade, como sujeito e finalidade da atividade econômica".

Por sua vez, a economia solidária é um instrumento de giro decolonial do saber econômico, tendo em vista o seu caráter de valorização do conhecimento local e a possibilidade de reconfiguração da rede em que o conhecimento local se constitui, conforme será fundamentado a seguir.

De uma maneira geral, a economia solidária valoriza a comunidade, suas tradições e saberes. De acordo com Lisboa (2005, p.110), a economia solidária "se enraiza no artesanato e nas economias com identidades locais e regionais". Assim, conclui a autora $(2005$, p.109) :

A expressão economia solidária designa inúmeras experiências que incluem formas diversas de agricultura familiar; assentamentos do MST; empresas industriais ou rurais recuperadas por meio da autogestão; cooperativas; redes de catadores e recicladores; redes nacionais e internacionais de comércio justo; incubadoras de empresas; cooperativas populares; inúmeras experiências de finanças solidárias; clubes de trocas e as economias indígenas e dos quilombos.

O motivo da valorização deste conhecimento da comunidade é o seu pertencimento ao grupo, sendo considerado uma competência coletiva (RETOUR e KROHMER, 2011). Uma competência coletiva se expressa por meio das ações de um grupo de trabalho e por seus participantes.

É o saber fazer operacional próprio a um grupo que lhe permite atingir um desempenho fora do alcance de um único indivíduo ou superior à soma das habilidades individuais. Essas competências coletivas se concretizam no momento da ação individual dos participantes. (RETOUR apud GATTAI, 2014, p.38). 
Reconhecer as competências coletivas de uma comunidade é o que permite um arranjo da economia solidária, tendo em vista que utilizará as ações, conhecimento e rotinas locais. Assim, rompe com o conhecimento do colonizador, quando não busca desqualificar o conhecimento da comunidade, pormenorizado como folclore ou cultura, como foi assinalado, mas sim, como conhecimento que possibilite o seu sustento.

Neste sentido, a superação das lógicas da colonialidade não se dá apenas no nível da transformação dos sistemas econômicos, nem apenas na dimensão do modo de produzir conhecimento. Afinal, ambas as esferas da vida estão intrinsecamente imbricadas uma na outra. Conforme ensina CASTRO-GÓMEZ e GROSFOGUEL ( 2007, p.17):

Devemos entender que o capitalismo não é só um sistema econômico (paradigma da economia-política) nem tampouco é apenas um sistema cultural (paradigma dos estudos culturais/pós-coloniais em sua vertente 'anglo-saxã'), mas é uma rede global de poder, integrada por processos econômicos, políticos e culturais, cuja soma mantem todo o sistema.

No caso do modo de produção de vida e conhecimento hegemônico, o capitalismo repercute o princípio epistemológico que fundamenta o lucro econômico nas relações sociais e com o conhecimento. Essa lógica prioriza a descontextualização dos resultados do saber, ao mesmo tempo que produz conhecedores de especialidades, divididos, separados e alienados da totalidade em que se insere seu saber. Ou seja, funciona a partir da mesma estrutura da produção econômica capitalista:

(...) existe uma distribuição geopolítica do conhecimento e das línguas. As línguas e os conhecimentos funcionam como funciona a economia: mediante um sistema valorativo, que classifica assimetricamente a produção, o consumo, a distribuição e a circulação de bens. (GARCÉS, 2007, p.225)

Mesmo diante do empreendimento colonial, muitas outras formas de conhecer e estar no mundo resistem. Os povos tradicionais de todo o planeta seguem produzindo saberes que não atendem aos pressupostos da epistemologia eurocentrada Em constante contraposição a este último modelo, universalizante e hierarquizante, pode-se, portanto, falar em saber local. Manuela Carneiro da Cunha (1999) sistematizou o conceito da seguinte maneira:

Digo saber local porque, a meu ver, embora a expressão englobe a de saber tradicional 
ou de saber indígena, ela se presta menos a confusões. A escolha dos termos não é fortuita. Saber local, como aliás qualquer saber, refere-se a um produto histórico que se reconstrói e se modifica, e não a um patrimônio intelectual imutável, que se transmite de geração a geração. (...) Sendo o saber local um processo de investigação e recriação, o problema está antes na erosão das condições de produção desse saber. Pois qual a natureza daquilo que se transmite? Diria que tanto quanto e talvez mais do que informações, é sobretudo uma combinação de pressupostos, formas de aprendizado, de pesquisa e de experimentação. Se entendermos o tradicional como essa forma específica de se praticar ciência (e não como conteúdos ancestrais específicos), então a palavra tradicional passa a ser equivalente a local. (1999, p.157)

Como explicitado pela autora, o conhecimento nunca está, portanto, apartado da vida. Os chamados conhecimentos tradicionais visibilizam, se apoiam e dialogam com a diferença a partir do contexto, das relações sociais e das realidades que produzem. Os espaços e tempos de aprender e ensinar estão, portanto, intrinsecamente ligados aos processos sociais a que os sujeitos pertencem, se materializando no processo de trabalho. A aprendizagem depende de um vínculo estabelecido entre quem ensina e quem aprende. $\mathrm{O}$ conhecimento é produzido, transmitido e validado nos ritos, na convivência, nos processos produtivos. O intelectual quilombola Antônio Bispo dos Santos (2015, p.90) sintetiza esses pressupostos:

\begin{abstract}
Por que exatamente as deusas e deuses e/ou dinvindades dos ditos povos pagãos faz com que povos como os Yanomami e tantos outros que pensam a partir da lógica cosmovisiva politeísta detenham tanto saber? (...) Acredito que seja essa estreita relação dos povos de lógica cosmovisiva politeísta com os elementos vitais, uma das principais chaves para compreensão de questões que interessam a todos e a todas. Pois sem a terra, a água, o ar e o fogo não haverá condições sequer para pensarmos em outros meios.
\end{abstract}

Os regimes de conhecimento chamados aqui de saber local são processos de relação com a terra, com os deuses e com as pessoas que apontam para uma lógica de pensamento "plurista territorializado" (SANTOS, 2015, p.91). Assim, a alteridade epistêmica que apresentam articula-se necessariamente a outras lógicas de estar no mundo, incluindo-se aí, outras lógicas econômicas.

Interessado eminentemente em produzir alternativas ao capitalismo na Europa pós-guerra, o intelectual francês Marcel Mauss (1925) estudou a noção de dádiva, ou seja, a prática de dar, receber e retribuir presentes de modo que se apresentam, simultaneamente, como um ato desinteressado e obrigatório. Em seu profícuo ensaio, ele identifica um princípio heurístico nos regimes de troca que investigou. Segundo o autor (1925, p.309), "os fatos que estudamos são todos fatos sociais totais: isto é, eles 
põe em ação a totalidade da sociedade e de suas instituições" . Nesses processos, o objeto não está separado de seu primeiro proprietário; seu valor não é medido em termos monetários, mas em sua capacidade de constituir e/ou fortalecer vínculos entre coisas e pessoas que estão, potencialmente, misturadas.

Se, por um lado, a conquista colonial arrancou de vários povos seus territórios transformando-lhes em mão de obra, a colonialidade continua a expropriar-lhes as condições de possibilidade de produzir seus saberes, suas economias, seus mundos. No sistema-mundo capitalista, o poder do conhecimento está na possibilidade de transformar a ele e a seus resultados em commodities: tudo se vende, nada lhe escapa. Enquanto proposta de giro decolonial, o que a chamada economia solidária pode fazer é reconfigurar a rede em que o conhecimento local se constitui, re-tramando a comunidade. O saber descontextualizado, alheio a quem trabalhando o põe em operação, não traz de volta nenhum poder ou autonomia. Assim, os empreendimentos solidários, ao proporem a posse coletiva dos meios de produção e dos frutos do trabalho, têm a potência de re-criar as condições de produção do saber local, na medida em que reestabelecem a trama comunitária.

No entanto, há que atentar para o fato que apenas valorizar conteúdos específicos, considerados tradicionais, não garante que os sistemas de saber local serão fortalecidos:

O curioso destes tempos de capitalismo global é que os conhecimentos indígenas são depreciados no contexto do uso das línguas modernas e do domínio da máquina desenvolvimentista e cientificista atual, mas, ao mesmo tempo, há um saque do conhecimento coletivo das comunidades camponesas e indígenas do planeta. Ou seja, enquanto se desqualifica, em nome da ciência e do progresso, os saberes e as línguas das comunidades indígenas que veiculam esses saberes, ao mesmo tempo se busca, por um lado, promover acordos e implementar mecanismos legais que permitam o roubo desses conhecimentos e, por outro, apropriar-se das línguas que o veiculam (GARCÉS, 2007, p.229).

Assim, o desafio e os gargalos apresentados à economia solidária são equivalentes e articulados aos dos saberes locais. No atual momento da economia do sistema-mundo, corre-se o risco de criar - apenas - um novo nicho de mercado para produtos e conhecimentos não-hegemônicos. A lógica do mercado capitalista tende a fagocitar os produtos e os processos de produção da economia solidária e seus saberes associados. Portanto, na dimensão econômica, é fundamental descolonizar as formas de trabalho enquanto que no campo epistemólogico, o desafio é não confinar o saber local 
à prisão da prática, mantendo-se assim, a mesma lógica binária da epistemologia eurocentrada. Como observado ao longo do artigo, há um imbricamento necessário entre a dominação, a exploração e o conflito para que a colonialidade se sustente no tempo e no espaço. Da mesma forma, saber local, processo de produção-circulaçãoconsumo e autonomia política não podem ser vividos e analisados desvinculados um do outro.

Diante desta construção, uma nova pergunta pode ser feita: Como a presença permanente dos três elementos (dominação, exploração e conflito) se inscreve no modo de produzir conhecimento e como o fortalecimento dos sistemas e processos de saber local pode contribuir para o enfrentamento à colonialidade do poder?

Em primeiro lugar, observa-se que o conhecimento produzido e/ou apropriado pela Europa/pelos europeus se (re)produz enquanto se funda com um poder de legitimidade não acionado para outros tipos de saber. Paralelo ao processo de exploração da terra via implementação de monocultivos de commodities manejados por pessoas escravizadas sob autoridade colonial, o conhecimento é gerado por poucos e em centros de poder, com vistas a produzir modos mais eficientes de dominação e exploração.

Historicamente, o surgimento da ciência positivista e do pensamento iluminista coincide, é impulsionado e retroalimenta o movimento colonial de domínio e exploração de outros continentes, como África e América. O processo de conquista é possibilitado, por um lado, pelo desenvolvimento de tecnologias bélicas, de navegação e de exploração/saque/genocídio da dos povos originários e seus recursos, e, por outro lado, por discursos pretensamente universalistas que justificam e legitimam a dominação de um povo sobre outros. Assim, enquanto as ciências duras constituiram-se enquanto modos objetivos de observação da natureza afim de descobrir leis universais aplicáveis a quaisquer contextos, a filosofia e o pensamento político forneciam as bases para produzir um sujeito racional e individual e para separar sua vontade da de Deus e do mundo natural ${ }^{5}$. Para Castro-Gómez e Grosfoguel (2007, p.20):

somente o conhecimento gerado pela elite científica e filosófica da Europa era tido como conhecimento 'verdadeiro', já que era capaz de abstrair de seus condicionamentos espaço-temporais para localizar-se em uma plataforma neutra de observação.

5 Para mais sobre o tema, ver: Mauss (2003[1938]) e Dumont (1985[1983]). 
Neste sentido, o saber legitimado ocidental fundamenta-se na divisão ontológica entre natureza (mundo) e cultura (pensamento humano). É esta articulação que o permite, epistemologicamente, a constituição de outras operações binárias, tais como as oposições entre sujeito e objeto, abstrato e concreto, privado e público, enfim, entre o domínio do universal e seu contrário, o particular.

É justamente este mecanismo de transformar uma particularidade em universalidade que cria os pressupostos teóricos e práticos para empreender e, simultaneamente, compreender como "o poder econômico e político que a Europa consegue acumular, a partir do século XVI, permite que se imponha seu habitus como norma, ideia e projeto universal para todos os povos do mundo" (GARCÉS, 2007, p.220). Assim sendo, a noção de universalidade advogada pelo conhecimento científico não apenas é parte de uma tradição local quanto também articula um movimento de colonização do mundo que forja as bases materiais e simbólicas para o advento do capitalismo.

Portanto, a história da produção, circulação e consumo dos conhecimentos dá pistas para compreendê-lo como estando sempre marcado geopoliticamente: "tem valor atribuído e um determinado lugar de origem; não existe conhecimento abstrato nem deslocalizado." (GARCÉS, 2007, p.226). Citando Castro-Goméz (2005) e Mignolo (1999a), os autores ainda afirmam que o discurso da modernidade guarda em si a armadilha da (falsa) necessidade de subir à epistemologia moderna para produzir verdadeiro conhecimento, não importando aonde no mundo se encontre. Neste ponto, é fundamental compreender que:

\footnotetext{
Em geral, os sistemas ocidentais de saber são considerados universais. No entanto, o sistema dominante também é um sistema local, com sua base social em uma determinada cultura, classe e gênero. Não é universal em sentido epistemológico. É apenas a versão globalizada de uma tradição local extremamente provinciana. Nascidos de uma cultura dominadora e colonizadora, os sistemas modernos de saber são, eles próprios, colonizadores. (SHIVA, 2003, p.21)
}

Se o conhecimento científico não é universal na dimensão epistemológica, ele se torna universalizante ao submeter a seus próprios critérios de validação qualquer outro produto do conhecimento de outros povos. Importante notar que este processo de aniquilação e apropriação dos saberes não ocorre de maneira isolada dos processos de dominação econômica, territorial e política: ao contrário, um é condição de 
possibilidade do outro.

\section{Conclusão}

O processo de colonização do saber econômico busca impor ao dito 'subalterno' teorias e conhecimentos dos povos europeus, desqualificando o conhecimento dos povos latinos ou de quaisquer outros que não sejam europeus. A premissa dos colonizadores perpassa pela ideia de que a "nossa ciência é a verdade e o pensamento de vocês é apenas um folclore". Assim, com o intuito de romper com a colonização do saber econômico eurocêntrico, este artigo busca evidenciar a possibilidade da utilização da economia solidária como instrumento de giro decolonial, especificamente, da epistemologia econômica do norte global.

Conforme brevemente demonstrado, a economia solidária é um instrumento de giro decolonial do saber econômico, tendo em vista seu caráter ligado à valorização do conhecimento local e a reconfiguração da rede em que o conhecimento local se constitui, re-tramando a comunidade. Pensar em formas de romper com a colonização do saber, principalmente econômico, empodera os 'subalternos', possibilitando uma nova forma de construção da sociedade para que sejam protagonistas das suas próprias histórias, equilibrar as relações de poder e propor novas formas de conhecimento, rompendo assim com a colonização do poder e do ser, em relação a "sociedade hegemônica.".

Observa-se ainda, como fruto das ponderações aqui correlacionadas, que a economia solidária requer uma ampla ação em termos de políticas públicas, como forma de potencializar as oportunidades do seu desenvolvimento como alternativa ao modelo universalizante e eurocêntrico de poder e saber atual. Com isso, experiências de expansão da economia solidária passariam a ser mais expressivas, constituindo-se potencialmente como um modo de produção alternativo no Brasil e no mundo.

Conforme demonstrado neste artigo, a economia solidária é um instrumento de giro decolonial ao romper com o saber, o ser e o poder eurocêntrico, reconhecendo o conhecimento dos povos tradicionais, como fator de produção importante que extrapola a visão capitalista hegemônica. Por fim, esta discussão não se esgota neste artigo merecendo ser objeto de futuros trabalhos e reflexões. 


\section{Referência bibliográfica}

BALLESTRIN, Luciana. América Latina e o giro decolonial. Revista Brasileira de Ciência Política. 2013, n.11, pp. 89-117

BRASIL, MINISTÉRIO DO TRABALHO E EMPREGO. O que é economia solidária? 2014. Disponível em: <http://portal.mte.gov.br/ecosolidaria/o-que-e-economiasolidaria.htm>. Acesso em 14 de abril de 2015

CASTRO-GÓMEZ, Santiago. Decolonizar la universidad. La hybris del punto cero y el diálogo de saberes. In: El giro decolonial: reflexiones para una diversidad epistémica más allá del capitalismo global / compiladores Santiago Castro-Gómez y Ramón Grosfoguel. - Bogotá: Siglo del Hombre Editores; Universidad Central, Instituto de Estudios Sociales Contemporáneos y Pontifi cia Universidad Javeriana, Instituto Pensar, 2007.

CASTRO-GÓMEZ, Santiago; GROSFOGUEL, Ramón (Ed.). El giro decolonial: reflexiones para una diversidad epistémica más allá del capitalismo global. Siglo del Hombre Editores, 2007.

CUNHA, Manuela Carneiro da. Populações tradicionais e a Convenção da Diversidade Biológica. Estudos Avançados, 13(36) pp.147-163.

DE MELO LISBOA, Armando. Economia solidária e autogestão: imprecisões e limites. RAE-Revista de Administração de Empresas, v. 45, n. 3, p. 109-115, 2005.

DE FRANÇA FILHO, Genauto Carvalho de. Terceiro setor, economia social, economia solidária e economia popular: traçando fronteiras conceituais.Bahia Análise \& Dados, v. 12, n. 1, p. 9-19, 2002.

DE FRANÇA FILHO, Genauto Carvalho; LAVILLE, Jean-Louis. Economia solidária: uma abordagem internacional. UFRGS Editora, 2004.

DUBEUX, Ana; MEDEIROS, Alzira; VILAÇA, Mônica; SANTOS, Shirley. A construção de conhecimento em economia solidária: Sistematização de experiências no chão de trabalho e da vida no Nordeste. Pernambuco: F\&A Gráfica e Editora Ltda, 2012.

DUPAS, Gilberto. O mito do progresso. Editora Unesp, 2006.

DUSSEL, Enrique. Introducción a una filosofía de la liberación latinoamericana, (II e III) 2000 .

DUMONT, Louis. $O$ individualismo: uma perspectiva antropológica da ideologia moderna.1985[1983]. Rio de Janeiro: Rocco.

ESCOBAR, Arturo. La invención del Tercer Mundo. Construcción y deconstrucción del desarrollo. Bogotá: Editorial Norma. 1996 (47 a 100).

GARCÉS, Fernando. Las políticas del conocimiento y la colonialidad lingüística y epistémica. : El giro decolonial: reflexiones para una diversidad epistémica más allá del capitalismo global / compiladores Santiago Castro-Gómez y Ramón Grosfoguel. - 
Bogotá: Siglo del Hombre Editores; Universidad Central, Instituto de Estudios Sociales Contemporáneos y Pontificia Universidad Javeriana, Instituto Pensar, 2007.

GATTAI, Silvia. As competências dos empreendedores solidários: estudo com catadores em cooperativas de coleta e tratamento de resíduos sólidos em São Bernardo do Campo. Tese de Doutorado. Universidade de São Paulo, 2014.

GROSFOGUEL, Ramón. Hacia um pluriversalismo transmoderno decolonial. Tabula Rasa, n.9, julho-dezembro, 2008.

Para descolonizar os estudos de economia política e os estudos pós-coloniais: transmodernidade, pensamento de fronteira e colonialidade global. Revista Crítica de Ciências Sociais, n. 80, p. 115-147, 2008.

GARCÉS, Fernando. Las políticas del conocimiento y la colonialidad lingüística y epistémica.In: El giro decolonial Reflexiones para una diversidad epistémica más allá del capitalismo global. 2007. Bogotá, Siglo del Hombre Editores.

MALDONADO-TORRES, Nelson. Sobre la colonialidad del ser: contribuciones al desarrollo de un concepto. In: El giro decolonial: refl exiones para una diversidad epistémica más allá del capitalismo global / compiladores Santiago Castro-Gómez y

MAUSS, Marcel. Ensaio sobre o Dom. In: Antropologia e Sociologia. 2003[1925]. São Paulo: Cosac Naif.

Uma categoria do espírito humano: a noção de pessoa, a de "eu”. In: Antropologia e Sociologia. 2003[1938]. São Paulo: Cosac Naif.

MIGNOLO, Walter. Desobediencia epistemica: a opção descolonial e o significado de identidade em política. Cadernos de Letras da UFF - Dossiê: Literatura, língua e identidade, no 34, p. 287-324, 2008.

NEAMTAN, Nancy. The social and solidarity economy: towards an 'alternative'globalisation. In: Background paper prepared for the symposium Citizenship and Globalization: Exploring Participation and Democracy in a Global Context. 2002. p. 14-16.

OLIVEIRA, Paulo de Salles. Entrevista. Estudos Avançados, vol. 22, nº 62. Jan-abril São Paulo, 2008.

PONTES, S.; TAVARES, M. A Universidade Federal da Integração Latino Americana (UNILA): um estudo da inclusão da diversidade epistemológica numa perspectiva não hegemônica. Congreso Iberoamericano de Ciencia, Tecnología, Innovación y Educación, 2014.

QUIJANO, Aníbal. "Colonialidad del Poder, Eurocentrismo y América Latina". En: Edgardo Lander (ed.). La colonialidad del saber. Eurocentrismo y ciencias sociales. Perspectivas latinoamericanas. Buenos Aires, CLACSO. 2000.

RETOUR, Didier; KROHMER, Cathy. A competência coletiva: uma relação-chave na gestão das competências. RETOUR, D. et al. Competências coletivas: no limiar da estratégia. Porto Alegre: Bookman, p. 45-78, 2011. 
RODRÍGUEZ, Ileana. "Subalternismo". Diccionario de Estudios Culturales Latinoamericanos. Mónica Zsurmuck, Robert Mckee (coord.). México: Siglo XXI editores, 2009.

SANTOS, Antônio Bispo dos. Colonização, Quilombos. Modos e significações. 2015. Brasília: INCTi.

SARAIVA, Regina Coelly Fernandes; DA SILVA CRUZ, Tânia Cristina. A cultura, os saberes e a tradição no arranjo da economia solidária ambiental.Cadernos de Agroecologia, v. 9, n. 3, 2014.

SINGER, Paul. Finanças solidárias e moeda social. FELTRIM, Luiz E.; VENTURA, Elvira CF; DOLD, Alessandra Von B. Projeto inclusão financeira. Brasília: Banco Central do Brasil, 2009. 2002. Introdução à economia solidária. $1^{a}$ ed. São Paulo: Fundação Perseu Abramo,

SHIVA, Vandana. Monoculturas da mente. São Paulo: Gaya. 2002.

TIBURCIO, Breno Aragão; VALENTE, Ana Lucia EF. O comércio justo e solidário é alternativa para segmentos populacionais empobrecidos? Estudo de caso em Território Kalunga (GO). Revista de Economia e Sociologia Rural, v. 45, n. 2, p. 497-519, 2007.

WALSH, Catherine. Interculturalidad y colonialidad del poder. Un pensamiento y posicionamiento "otro" desde la diferencia colonial. In: El giro decolonial: reflexiones para una diversidad epistémica más allá del capitalismo global / compiladores Santiago Castro-Gómez y Ramón Grosfoguel. - Bogotá: Siglo del Hombre Editores; Universidad Central, Instituto de Estudios Sociales Contemporáneos y Pontificia Universidad Javeriana, Instituto Pensar, 2007.

\section{A Economia Solidária como um Instrumento de giro Decolonial do saber Econômico Capitalista}

Resumo

O capitalismo influencia as formas de produção, estruturas sociais e relações humanas da nossa sociedade. A colonialidade do saber econômico reproduz e submete aos subalternos suas perspectivas, seus objetivos, estruturas e dinâmicas. Assim, a proposta deste trabalho é sugerir o desenvolvimento da economia solidária como alternativa de produção do saber econômico, com a finalidade de promover conhecimentos e práticas que possibilitem um giro decolonial.

Palavras-chave: giro decolonial, economia solidária, colonialidade do saber, capitalismo

The Solidarity Economy as a Decolonial turn Intrument of the Capitalist Economic Knowlegde

Abstract
Capitalism influences the forms of production, social structures and human relations in our society. The
economic coloniality of knowledge, reproduces and submits at subaltern its prospects, objectives, 
structures and dynamics So the purpose of this paper is to suggest the development of the solidarity economy as an alternative economic production of knowledge, in order to promote knowledge and practices to enable one decolonial turn.

Keywords: decolonial turn, solidarity economy, coloniality of knowledge, capitalism

\section{La Economía Solidaria como un Instrumento de giro Decolonial del saber Económico Capitalista}

\section{Resumen}

El capitalismo influye en las formas de producción, estructuras sociales y relaciones humanas de nuestra sociedad. La colonialidad del saber económico reproduce y somete a los subalternos sus perspectivas, sus objetivos, estructuras y dinámicas. Así, la propuesta de este trabajo es sugerir el desarrollo de la economía solidaria como alternativa de producción del saber económico, con la finalidad de promover conocimientos y prácticas que posibiliten un giro decolonial.

Palabras clave: giro decolonial, economía solidaria, colonialidad del saber, capitalismo 